\title{
Who is the next for aortic valve implantation? Present and future indications
}

\section{Giuseppe Verolino, Alessia Delli Veneri, Myriam Carpenito, Francesco Piccirillo, Leonardo Aurino, Annunziata Nusca}

Department of Cardiac Sciences, Campus Bio-Medico University of Rome, Rome 00128, Italy.

Correspondence to: Dr. Annunziata Nusca, Unit of Cardiovascular Science, Campus Bio-Medico University of Rome, Via Alvaro del Portillo 200, Rome 00128, Italy. E-mail: a.nusca@unicampus.it How to cite this article: Verolino G, Delli Veneri A, Carpenito M, Piccirillo F, Aurino L, Nusca A. Who is the next for aortic valve
implantation? Present and future indications. Vesse/ Plus 2018;2:17. http://dx.doi.org/10.20517/2574-1209.2018.32

Received: 14 May 2018 First Decision: 5 Jul 2018 Revised: 14 Jul 2018 Accepted: 19 Jul 2018 Published: 2 Aug 2018

Science Editor: Cristiano Spadaccio, Mario F. L. Gaudino Copy Editor: Jun-Yao Li Production Editor: Huan-Liang Wu

\begin{abstract}
Aortic valve stenosis (AS) represents the most prevalent valvular defect worldwide. It is a progressive disease with a long latency interval and a poor prognosis after symptoms present. According to current European Society of Cardiology guidelines, transcatheter aortic valve implantation (TAVI) is recommended in all patients with severe symptomatic AS and a predicted survival longer than one year, who are not suitable for surgical valve replacement. Despite these recommendations, several studies over the past few years suggest extending these indications towards lower risk AS populations. Otherwise, current available operative risk scores such as Society of Thoracic Surgeons score and EuroSCORE, may offer an incomplete risk assessment; in this setting, the Heart Team plays a crucial role in defining the most appropriate therapeutic strategy in patients with AS. In this review, we aim to discuss the current and future indications for TAVI, analyzing available literature according to patients' profile risk (high/mid/low risk) and other specific conditions (valve-in-valve, bicuspid valve and pure aortic regurgitation).
\end{abstract}

Keywords: Aortic valve implantation, aortic stenosis, structural valve intervention, bicuspid valve, valve-in-valve

\section{INTRODUCTION}

Aortic valve stenosis (AS) is the most prevalent valvular defect worldwide. It mainly affects elderly patients; it is a progressive disease with a long latency phase that, however, has a poor prognosis after symptoms of dyspnoea, angina or syncope occur. Despite significant strides in medical therapy for several other cardiovascular pathological conditions, little progress has been made in medical therapy for AS. Observational studies demonstrated a mortality rate of $75 \%$ in patients with AS within 3 years of the symptom onset unless

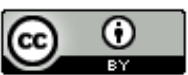

(C) The Author(s) 2018. Open Access This article is licensed under a Creative Commons Attribution 4.0 International License (https://creativecommons.org/licenses/by/4.0/), which permits unrestricted use, sharing, adaptation, distribution and reproduction in any medium or format, for any purpose, even commercially, as long as you give appropriate credit to the original author(s) and the source, provide a link to the Creative Commons license, and indicate if changes were made.

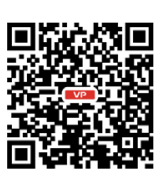


the outflow obstruction is removed by aortic valve intervention ${ }^{[1]}$. Surgical aortic valve replacement (SAVR) has been the gold standard treatment for a long time; however, with ageing and increasing multimorbidity of AS population, the need for a less invasive approach was clearly identified in the first European Heart Survey, where a significant number of patients, about $42 \%$, were not referred or accepted for surgery ${ }^{[2]}$. The introduction of percutaneous treatment for severe AS with transcatheter aortic valve implantation (TAVI) remains one of the latest and greatest achievements in interventional cardiology. Since Cribier et al ${ }^{[2]}$ reported the first "proof-of-concept" case of TAVI in 2002, more than 200,000 patients have undergone this procedure in approximately 65 countries. Starting off as a new approach for high-risk patients, TAVI has nowadays proved to be the best strategy in frail patients and is becoming increasingly seen as a very interesting option for those with intermediate risk. Recently, increased operator experience and improved device systems have led to consider the extension of this therapeutic strategy also to low-risk patients. Thus, in this intriguing setting, this review summaries the present and future indications of TAVI.

\section{CURRENT GUIDELINES RECOMMENDATIONS}

The current guidelines of the European Society of Cardiology (ESC)/European Association for CardioThoracic Surgery (EACTS) on valvular heart diseases established that the choice for intervention, SAVR vs. TAVI, should be based on a careful evaluation of patients' procedural risk and technical suitability, thus a precise assessment of risks/benefits balance of each modality ${ }^{[3]}$. Importantly, local expertise and outcomes data for both surgical and percutaneous intervention must be carefully evaluated and the Heart Team has to play a fundamental role in the final therapeutic decision of AS patients. Thus, the selection of TAVI vs. SAVR should involve a multidisciplinary discussion between cardiologists, surgeons, imaging specialists, anesthesiologists, and other specialists if necessary ${ }^{[3]}$.

In view of this, according to ESC guidelines, TAVI is recommended in all patients with severe symptomatic AS and a predicted survival greater than one year who are not eligible for SAVR (Class IB) ${ }^{[3]}$. Data supporting this indication has been presented in many European registries such as the CoreValve Extreme Risk Registry and from the randomized Placement of AoRTic TraNscathetER valves (PARTNER I B) study ${ }^{[4-7]}$. However, in this setting, the definition of "inoperable patient" has been problematic because it comes from score systems usually used for surgical population (Society of Thoracic Surgeons - STS or EuroSCORE II), that are not able to capture all comorbidities that make a patient an inadequate candidate for conventional surgery. Over the last few years, it has become clear that other factors such as frailty and anatomical features (porcelain aorta, "hostile chest", liver disease, substernal location of a mammary graft) needed to be considered. Thus, the central element to evaluate whether patients are at high risk for surgery remains clinical judgment: the ability to integrate a quantitative assessment based on the traditional surgical risk scores and other important clinical features observed in the "real world" AS population but not included within score systems.

The current ESC guidelines also recommend that TAVI should be considered an alternative to SAVR in severe AS patients who are at high risk for mortality and complications after conventional surgery, thus those with STS or EuroSCORE II $\geq 4 \%$ or logistic EuroSCORE I $\geq 10 \%{ }^{\left[{ }^{3}\right]}$. Of note, TAVI should be favored in elderly patients eligible for transfemoral access as suggested by registries and two important randomized controlled trials comparing TAVI vs. SAVR: the PARTNER I A trial, using a balloon-expandable device, and the CoreValve High-Risk study with a self-expandable valve ${ }^{[8,9]}$. Similar recommendations are reported by the American Heart Association/American College of Cardiology (AHA/ACC) Guidelines for the management of patients with valvular heart disease ${ }^{[10]}$. They recommend a global risk assessment resulting in a 4-group classification (low, intermediate, high and prohibitive risk) according to STS score value ( $<4 \%$ in low risk, between $4 \%$ and $8 \%$ in intermediate risk, $>8 \%$ in high risk), presence or not of frailty, impairment in 1 or more major organ systems (no comorbidity in low risk, 1 organ system in intermediate risk, 2 in high 
Table 1. Indications for aortic valve implantation according to the ESC/EACTS and ACC/AHA

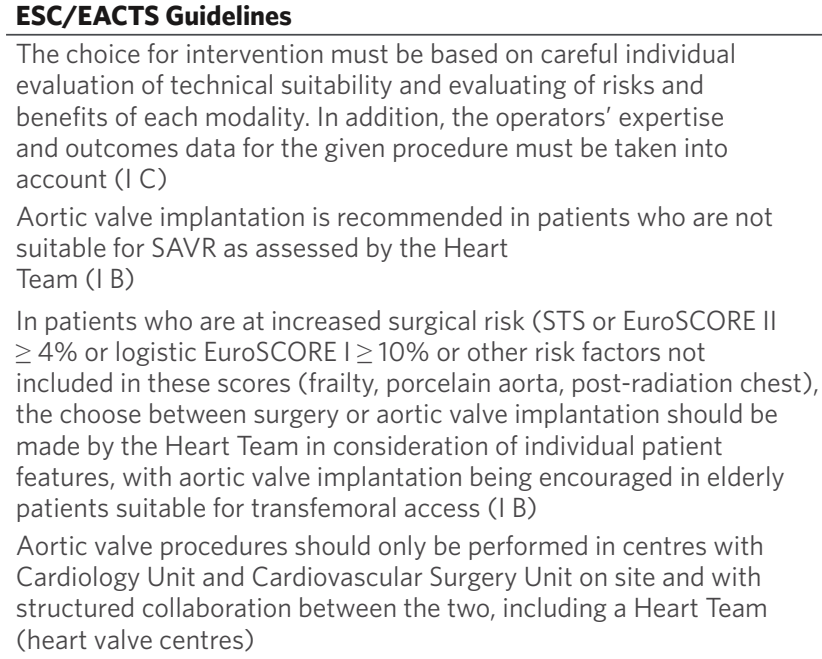

The choice for intervention must be based on careful individual evaluation of technical suitability and evaluating of risks and benefits of each modality. In addition, the operators' expertise and outcomes data for the given procedure must be taken into account (I C)

Aortic valve implantation is recommended in patients who are not suitable for SAVR as assessed by the Heart

Team (I B)

In patients who are at increased surgical risk (STS or EuroSCORE II $\geq 4 \%$ or logistic EuroSCORE I $\geq 10 \%$ or other risk factors not included in these scores (frailty, porcelain aorta, post-radiation chest), the choose between surgery or aortic valve implantation should be made by the Heart Team in consideration of individual patient features, with aortic valve implantation being encouraged in elderly patients suitable for transfemoral access (I B)

Aortic valve procedures should only be performed in centres with Cardiology Unit and Cardiovascular Surgery Unit on site and with structured collaboration between the two, including a Heart Team (heart valve centres)

(IC)

\section{ACC/AHA Guidelines}

TAVR is recommended for symptomatic patients with severe AS and high risk for SAVR, depending on patient specific procedural risk, values and preferences (I A)

TAVR is recommended for symptomatic patients with severe AS, extremely high risk for SAVR, and predicted postprocedure survival greater than 12 months (I A)

TAVR is a reasonable alternative to SAVR for symptomatic patients with severe AS and intermediate surgical risk, depending on patient-specific procedural risk, values and preferences (Ila B)

For severely symptomatic patients with bioprosthetic stenosis or regurgitation at high of prohibitive risk for reoperation, and in whom improvement in hemodynamics is anticipated, valve in valve TAVR is feasible (Ila B)

ACC: American College of Cardiology; AHA: American Heart Association; AS: aortic stenosis; EACTS: European Association for CardioThoracic Surgery; ESC: European Society of Cardiology; STS: Society of Thoracic Surgeons Risk Score; TAVR: transcatheter aortic valve replacement

risk) and procedural impediments (absent in low risk and minimal or possible in intermediate and high risk, respectively). The fourth group (prohibitive risk) doesn't consider STS risk score, but pre-operative risk of mortality and morbidity at 1 year $>50 \%, \geq 3$ compromised major organ systems not to be improved postoperatively, severe frailty, or severe impediments linked to procedure ${ }^{[10]}$.

According to this classification, TAVI is recommended in patients with prohibitive surgical risk and is considered a reasonable alternative to conventional surgery in those with high risk. In Table 1, indications for TAVI according to the ESC/EACTS and ACC/AHA are reported.

\section{HIGH-RISK PATIENTS}

Untreated AS has been conventionally considered a terminal condition for patients refusing high-risk surgical valve replacement or those deemed not operable candidates by treating physicians ${ }^{[1]}$. Surgical aortic valve replacement has demonstrated to improve symptoms and long-term prognosis; however, observational studies identified subgroups of patients, such as those elderly or with reduced ejection fraction, that are at increased surgical risk for procedural complications or death anyway ${ }^{[12]}$. As regards these patients, a less invasive treatment would be a desirable alternative ${ }^{[8]}$ and, for this reason, over the last decade TAVI has been identified as the standard of care for high-surgical risk patients or for those considered inoperable by surgeons. TAVI has demonstrated the potential to decrease the morbidity associated with standard SAVR owing to the avoidance of a median sternotomy, cardiopulmonary bypass and cardioplegic arrest. Nevertheless, the selection process towards TAVI needs thoughtful consideration of risks and benefits of the procedure and a comparison of these factors with alternative therapies ${ }^{[13]}$. The EACTS/ESC Guidelines recommend four main steps for patient selection before TAVI procedure: severity of valve stenosis and symptom confirmation, assessment of the technical feasibility, exclusion of contraindications, and accurate clinical examination for surgical risk assessment based on validated scores ${ }^{[14]}$.

Also given these guidelines, a EuroSCORE $>20 \%{ }^{[15]}$ or a STS $>10 \%{ }^{[16]}$ has been used to identify "high-risk" patients. It has also been recognized that factors such as frailty, associated with adverse outcomes and actu- 
ally not incorporated within current models ${ }^{[17]}$, should be considered. Of note, frailty is related to different factors and several scores have been proposed to measure it. Therefore, Anand et al. ${ }^{[18]}$ indicate frailty evaluation like a marker of physiological reserve and concomitantly a prognostic index. An overall assessment by score systems also led to identification of patients in whom aortic valve replacement would be futile. Nishimura at al. recognized that valve interventions are likely to be futile in patients with a life expectancy less than 1 year or a likelihood of "survival with benefit" less than $25 \%$ at 2 years (improvement in quality of life or life expectancy or improvement in heart failure or angina class) ${ }^{[19]}$.

Several randomized trials reported similar outcome results between TAVI and SAVR in the high-risk population and the benefit of a percutaneous strategy in patients not suitable for surgery compared with optimal medical treatment. The PARTNER I was the first large randomized trial conducted using a balloonexpandable device (Edwards Sapien Valve) to test the effectiveness of TAVI and the publication of its 1-year outcomes has really redefined the conventional wisdom ${ }^{[8,20]}$. Patients were divided into two groups: the first one with patients who were considered available for surgery although a high surgical risk (Cohort A, $n=$ 699 , STS risk score $>10 \%$ or a predicted risk of death by 30 days after surgery of $15 \%$ or higher derived from other comorbidities), and the second one (Cohort $\mathrm{B}, n=358$ ) with patients who have a real contraindication for surgery because of coexisting conditions that would be associated with a predicted probability of $50 \%$ or more of either death by 30 days after surgery or a serious irreversible condition ${ }^{[21]}$. In the Cohort A, patients undergoing TAVI showed similar 1-year all-cause mortality rate compared with SAVR group (24.2\% vs. 26.8\%; $P=0.001$ for non-inferiority ${ }^{[11]}$. Reported 5 -year results were comparable as well, with a mortality rate observed in $67.8 \%$ of patients receiving TAVI $v s .62 .4 \%$ of those treated with SAVR $(P=0.76)^{[2]}$. The prevalence of stroke was $3.8 \%$ and $2.1 \%$, respectively $(P=0.2)$, although for all neurologic events, the difference between TAVI and SAVR was significant $(P=0.04)$, including $4.6 \%$ for femoral artery access transcatheter replacement vs. $1.4 \%$ for open surgery $(P=0.05)$. In patients deemed not to be candidates for surgery (Cohort $\mathrm{B})$, TAVI was superior to standard therapy with significantly reduced 1-year all-cause mortality ( $30.7 \% v s .50 .7 \%$; $P=0.001)^{[11]}$. Recently 5 -year follow-up data for this cohort have been reported; principal findings were a mortality rate of $71.8 \%$ in the TAVI group compared with $93.6 \%$ of patients on medical therapy. Similarly, cardiovascular mortality (57.5\% vs. $85.9 \%$, HR 0.41, 95\% CI: $0.31-0.55, P<0.0001)$ and repeat hospitalizations ( $47.6 \%$ vs. $87.3 \%, P<0.0001$ ) were significantly lower in the TAVI arm at 5 years ${ }^{[23]}$. The Medtronic CoreValve US Pivotal Trial confirmed these results; in this series, the self-expandable Medtronic CoreValve implantation was associated with a $40 \%$ reduction in the primary endpoint (combined of all-cause mortality and stroke) at 1-year follow-up in the "extreme risk" arm ${ }^{[9]}$. Also, several registries reflecting real-life TAVI experience confirmed the effectiveness and safety of TAVI in elderly patients with AS, considered at high-risk and in whom the percutaneous approach appeared to be a reasonable and convincing option. The FRANCE 2 Registry enrolled all TAVI performed in 34 centers in France and Monaco, without selection bias ${ }^{[5]}$, including 3195 procedures; of those, $80.4 \%$ were percutaneous and 19.6\% were surgical. The overall 30 -day mortality was $9.7 \%$ (8.5\% in the transfemoral group and $13.9 \%$ in the transapical group), a percentage closer to those previously reported by other registries ${ }^{[24,25]}$ but higher compared with randomized trials, probably related to high-risk profile of enrolled patients ${ }^{[11]}$. On the other hand, the 1-year survival rate of $76 \%$ was comparable with randomized data. At the multivariate analysis, logistic EuroSCORE, NYHA functional class III or IV, the use of transapical approach and the presence of post-procedural periprosthetic regurgitation grade of 2 or more have been demonstrated independent predictors of mortality after 1-year from procedure.

Thus, according to these findings and guideline recommendations for the management of surgical high-risk patients, it is not surprising that this technique has found widespread use in this subset of patients.

\section{INTERMEDIATE AND LOW RISK PATIENTS}

Recently several studies have focused their attention on the large proportion of AS population defined at 
intermediate-risk (STS risk score between $4 \%$ and $8 \%$ ) and at low-risk (STS risk score $<4 \%{ }^{[26,27]}$. Under current guidelines, the choice to perform TAVI for that group of patients should be allowed only after a specific cases selection by the Heart Team and, importantly, in centers with well-established procedural training. Many trials are ongoing to demonstrate real advantage of TAVI in low risk subset but others have already been published which show the true benefits for intermediate risk patients.

The PARTNER II was the first large randomized trial that evaluated the outcome of TAVI in intermediate surgical risk population ${ }^{[28]}$. In this study Leon et al. ${ }^{[28]}$ randomized about 2000 patients with severe AS and STS score between $4 \%$ and $8 \%$ to TAVI [mean STS- Prediction of Mortality (PROM) 5.8\%] or SAVR. At 24-month follow-up, the composite endpoint of all-cause death or disabling stroke was $19.3 \%$ in the TAVI group compared with $21.1 \%$ in those treated with SAVR $(P=0.25)$. Of note, a significant interaction between TAVI approach and mortality was observed, with transfemoral TAVI showing superiority over SAVR (HR 0.79; 95\% CI: 0.62-1.00; $P=0.05$ ). Larger aortic valve areas, lower rates of acute kidney injury, severe bleeding, and new-onset atrial fibrillation were also reported in TAVI group, whereas, SAVR caused fewer major vascular complications and less paravalvular aortic regurgitation ${ }^{[28]}$. In the Surgical Replacement and Transcatheter Aortic Valve Implantation trial (SURTAVI), Reardon et al. ${ }^{[29]}$ confirmed the feasibility of TAVI in patients at intermediate risk (mean STS-PROM of 4.4\%). They observed an incidence of the same end point chosen in the PARTNER II trial (overall death and stroke) of $12.6 \%$ in patients receiving TAVI and of $14 \%$ in those undergoing conventional surgery. A pre-specified analysis of the single components of the primary end point has shown a similar rate of all-cause death between the two treatment strategies (11.4\% and $11.6 \%)$, whereas, at 24 months follow-up, a numerically lower rate of disabling stroke was found in the TAVI group compared with the surgical group, although the difference was not significant $(4.5 \% \text { vs. } 2.6 \%)^{[29]}$. Similar positive results have been demonstrated also in low-risk AS population. In the Nordic Aortic Valve Intervention Trial (NOTION), Thyregod et al. ${ }^{[30]}$ randomized 280 low-risk AS patients to TAVI or SAVR. The primary endpoint of death for any causes, myocardial infarction and stroke after 1 year was observed in $13.1 \%$ of the TAVI group and $16.3 \%$ of the SAVR group. The "intention to treat" analysis confirmed these results (11.3\% vs. $15.7 \%$, respectively in TAVI and SAVR groups). Moreover, the 5-year follow-up of the NOTION trial was recently reported at the latest ACC Congress ${ }^{[31]}$. After five years, there were no differences in the incidence of the composite primary end point (39.2\% of TAVI patients and $35.8 \%$ of SAVR patients). Looking at the endpoints individually, the rate of all-cause mortality was $27.7 \%$ for both SAVR and TAVI. In addition, stroke incidence was $10.5 \%$ in TAVI patients and $8.2 \%$ in those receiving SAVR, while $8.7 \%$ and $8.6 \%$ of patients had experienced a myocardial infarction in the TAVI and SAVR groups, respectively. These results were also observed for patients with STS score less than $4 \%{ }^{[31]}$. Similar evidence was reported by Wenaweser et al. ${ }^{[32]}$ comparing clinical outcomes of patients with intermediate/low-risk and high-risk patients undergoing TAVI. Patients with severe AS receiving TAVI showed a mortality rate of $3.9 \%$ and $2.4 \%$, respectively for mid and low risk groups $(P<0.001)$; these data are extremely positive and promising, especially in consideration of the expected mortality estimates of $6.8 \%$ according to STS-PROM score. Finally, in the Italian registry Observational Study of Effectiveness of SAVR-TAVI Procedures for Severe Aortic Stenosis Treatment (OBSERVANT $)^{[33]}$, enrolling patients surgical and TAVI treated, the 1-year mortality was not different in the two groups $(13.6 \%$ vs. $13.8 \%$; $P=0.936)$, even if in the first 90 days after aortic procedure, mortality was numerically greater in patients receiving SAVR compared with TAVI. Furthermore, in this last group, the rate of rehospitalization for cardiac symptoms and episodes of acute heart failure was lower $(21.9 \%$ vs. $23.6 \%$ and $19.0 \%$ vs. $19.7 \%$, respectively) ${ }^{[33]}$. Several trials such as PARTNER 3 and NOTION 2 are ongoing and could probably confirm the effectiveness and safety of transcatheter aortic approach compared with surgery also in the low-risk subgroup.

However, although results of previously reported studies are very encouraging, nobody can demonstrate a statistically relevant result that favours choosing TAVI in every patient, irrespective of risk profile. Moreover, 
major complications associated with TAVI should be considered such as the need for permanent pacemaker (PMK) (25.9\% at 30 days in the SURTAVI trial and $18.5 \%$ at 1 year in the OBSERVANT trial) and the development of paravalvular leaks, with an incidence of about $1 \%$ according to the recent literature findings ${ }^{[34]}$. Probably with increased operators' experience, longer learning curve and newer generation devices, these complications could be reduced. However, rehospitalization and mortality rates of patients undergoing PMK after TAVI were not higher compared with those who did not develop this complication. Moreover, only a small percentage of patients treated with TAVI has undergone a new procedure (valve-in-valve) or shifted to open surgery due to the development of large paravalvular leaks ${ }^{[35]}$. On the other side, two important elements arise from all these studies in favor of TAVI: reduced hospitalization time (in days) and lower incidence of new onset atrial fibrillation (AF). Length to stay in hospital is significantly shorter for TAVI patients than SAVR: in particular, 4 vs. 10 days was reported by Garcia et al. ${ }^{[36]}$ and 8.9 vs. 12.9 days in the NOTION trial $^{[31]}$. Similar results were observed also in the OBSERVANT registry $(8.8 v s .12 .6 \text { days, } P<0.001)^{[33]}$. In this century where spending review is a real concern, reduction of average length of stay in hospital is an important issue; obviously, no less important is an earlier patient's return to home with an overall positive advantage for public health (healthcare infection, lodging). On other hand, AF is the most frequent rhythm disease with several aspects that significantly deteriorate patient quality of life and long-term prognosis. Several studies showed that SAVR is burdened with a higher incidence of AF compared with TAVI; in the NOTION study, about 59.4\% of patients developed AF after 1 year from surgery compared with only $21.2 \%$ of patients undergoing TAVI $(P<0.001)^{[31]}$. Leon et al ${ }^{[28]}$ confirmed these findings in the PARTNER 2 trial reporting an incidence of new onset AF of $11.3 \%$ and $27.3 \%$ in the TAVI and SAVR groups, respectively. In the SURTAVI trial, the incidence of AF was higher after SAVR (43\% after 30 days) than in the TAVI group ${ }^{[2]]}$.

Finally, another important issue that should be considered for TAVI as a routinely procedure especially in low-risk population is valvular degeneration. Actually, poor data are available to define the durability of prostheses in young patients with life expectancy $>20$ years. Otherwise, there is not yet a clear definition of "prothesis degeneration". One of those currently used, according to Valve Academic Research Consortium (VARC 2) definition, is based on specified echocardiographic criteria: mean aortic valve gradient $\geq 20 \mathrm{mmHg}$, EOA (effective orifice area) $\leq 0.9-1.1 \mathrm{~cm}^{2}$, DVI (Doppler velocity Index) $<0.35 \mathrm{~m} / \mathrm{s}$, and/or moderate or severe prosthetic valve regurgitation ${ }^{[34]}$. Thus, a specific trial is needed to evaluate long-term outcomes in a selected population with low-risk profile. Surely TAVI may be considered even as first option in a population with intermediate-risk and, where patient agrees, also in a low risk profile.

\section{PATIENTS WITH BICUSPID AORTIC VALVE}

Bicuspid aortic valve (BAV) is one of the most common congenital valve abnormalities, occurring in $0.7 \%$ $2 \%$ of the general population. BAV is related to a higher valve shear stress, favouring leaflet calcification and degeneration and AS and/or aortic regurgitation (AR) development ${ }^{[37]}$. BAV has been considered for a long time as a relative contraindication to TAVI, first of all for the higher expected risk for relevant AR. Furthermore, the unfavorable anatomy of BAV may interfere with the appropriate positioning and expansion of the prosthetic valve, theoretically increasing the incidence of procedural complications as well as decreasing the efficacy and durability of the prosthetic valve ${ }^{[8,20]}$.

Different studies were conducted to evaluate the relative benefits of TAVI in patients with BAV. Bauer et al. ${ }^{[38]}$, within the German TAVI Registry, prospectively enrolled 1424 patients with severe AS undergoing TAVI from January 2009 to June 2010. They compared TAVI outcomes in patients with BAV $(n=38,3 \%)$ and those with tricuspid aortic valve (TAV) (TAV; $n=1357,97 \%$ ). They observed that PMK implantation occurred more frequently in patients with TAV $(17 \% v s .35 \%, P=0.02)$, whereas a greater rate of relevant AR was observed among patients with BAV after the transcatheter procedure $(25 \% v s .15 \%, P=0.05)$. Of note, despite the higher risk for relevant AR among patients with BAV compared with those with TAV, 30-day and 1-year mortality rates were similar in both subsets of patient ${ }^{[38]}$. A systematic review and meta-analysis conducted 
by Phan et al ${ }^{[39]}$ analyzed seven studies including a total of 2245 patients (149 with BAV and 2096 with TAV) undergoing TAVI. According to their results, no difference was observed in 30-day mortality between BAV and TAV groups. Moreover, no difference was found in post-TAVI mean peak gradients, grading of paravalvular leaks (moderate or severe) $(25.7 \%$ vs. $19.9 \%$ respectively, $P=0.29)$, PMK implantations rate $(18.5 \%$ vs. $27.9 \%, P=0.52)$, life-threatening bleeding $(8.2 \%$ vs. $13.9 \%, P=0.33)$ and major bleeding $(20 \%$ vs. $16.8 \%$, $P=0.88)$. Furthermore, need for conventional open-heart surgery (1.9\% for BAV group and $1.2 \%$ for TAV group, $P=0.18)$ and occurrence of vascular complications $(8.6 \%$ and $10.1 \%$ respectively, $P=0.32)$ were also comparable between the two groups ${ }^{[39]}$. Confirming these findings, Sannino et al. ${ }^{[40]}$ investigated the efficacy and safety of TAVI in BAV population. From January 2012 to February 2016, 823 consecutive patients with severe AS (735 with TAV and 77 with BAV) undergoing TAVI were retrospectively enrolled. Definition of a successful procedure was established assessing postprocedural valve function, thus measuring echocardiographic parameters such as mean gradient, peak velocity, effective orifice area and evaluating the presence of paravalvular leak at least of moderate degree. Safety was evaluated by 30-day and 1-year mortality for any causes, immediate postprocedural mortality and 30-day cardiovascular mortality, procedural success, pacemaker implantation, and development of procedural complications. No significant differences in in-hospital mortality (1.1\% in BAV group vs. $0.8 \%$ in TAV group), 30-day cardiovascular mortality (3.4\% vs. 2.3\%), 30day all cause mortality $(3.4 \% v$ s. $3.1 \%)$ and 1-year all cause mortality $(8.5 \% v s .10 .5 \%)$ were found between the two groups ${ }^{[40]}$.

In conclusion, according to the current evidence, bicuspid anatomy should not be excluded from TAVI: transcatheter valve replacement is deemed a safe and useful procedure both in inpatients with TAV and in those with BAV.

\section{PATIENTS WITH PURE AORTIC REGURGITATION}

Nowadays, TAVI procedure for native AR treatment has a marginal role, mainly as "off-label" application in very high-risk patients. TAVI for pure native AR has been shown to be more difficult and associated with lower procedural success, safety, and clinical efficacy rates ${ }^{[41]}$. Possible explanations for this limited success are related to the concept that a certain amount of aortic annulus and/ore valve calcification is necessary to anchor a balloon- or self-expandable transcatheter valve prosthesis into the annulus ${ }^{[2]}$. However, limited data exist about safety and efficacy of TAVI in this specific subset of patients, mainly reported in several case reports and small clinical studies. Yoon et al. ${ }^{[42]}$ enrolled 331 patients with symptomatic, severe pure native AR undergoing TAVI across 40 participating centers between September 2007 and February 2017. The aim of this study was to compare the outcomes of TAVI with early- and new-generation prosthesis devices in symptomatic patients with pure AR. Compared to the early-generation devices, the new ones were associated with a significantly higher device success rate $(81.1 \%$ vs. $61.3 \%, P<0.001)$ due to lower rates of second valve implantation and post-procedural AR (more than moderate). The cumulative rates of all-cause and cardiovascular death at 1-year follow-up were similar and post-procedural AR was independently associated with worse outcomes ${ }^{[42]}$. Similar findings were showed by Franzone et al. ${ }^{[43]}$ that confirmed TAVI as technically feasible in AR patients, with acceptable early morbidity and mortality rates ${ }^{[43]}$. Overall, the rates of complications and of residual moderate or severe AR were low; the main complication was the need of a second valve implantation ${ }^{[43]}$. Furthermore, in a large international registry, Sawaya et al. ${ }^{[4]}$ described their experience with TAVI when used to treat patients with severe AR, both those with native AR and those with failing bioprosthetic surgical heart valves ( $n=146,78$ with native AR and 68 with failing surgical devices). Also in this study, TAVI for pure AR was associated with higher occurrence of device embolization/migration and significant paravalvular regurgitation especially with old-generation transcatheter heart valves. However, new-generation devices significantly improved procedural success and clinical efficacy compared to old ones, suggesting that also in patients with failing surgical prostheses, TAVI may represent a valuable therapeutic option ( $85 \%$ vs. $54 \%$ and $75 \%$ vs. $46 \%$, respectively $P<0.05)^{[44]}$. However, further studies and new 
device technology are needed before considering TAVI as a reasonable treatment option for pure AR.

\section{PATIENTS WITH DEGENERATIVE BIOPROSTHETIC SURGICAL VALVES: THE VALVE IN VALVE STRATEGY}

As previously reported, TAVI is a useful procedure for the treatment of patients with native AS judged to have high/intermediate surgical risk ${ }^{[2,45,46]}$. However, over the last years, another "off-label" use of TAVI is also emerging in practice: the so-called "valve in valve" (VIV) ${ }^{[47,48]}$. Bioprostheses are known to have a limited durability, degenerating in a period of about $10-20$ years $^{[49]}$. Although reoperation ("redo" surgery") is considered the gold standard treatment for this population, it represents a procedure associated with high risk of morbidity and mortality. Maganti et al. ${ }^{[50]}$ observed a poor 5 -year survival $(67 \% \pm 5 \%)$ in a cohort of patients aged 75 years or older who underwent redo valve surgery. According to these findings, transcatheter aortic VIV implantation has emerged as a viable and less-invasive technique to be used in this setting and to obviate the need for reoperation. Despite being a technique still in progress, performed especially in specialized centers, a worldwide register is now available (Global Valve-in-Valve Registry) ${ }^{[51]}$, aiming to evaluate the effectiveness and clinical results of this technique in a wide cohort of patients. Before the creation of this register, previous studies investigating the VIV technique included only a small number of cases and were therefore limited in providing conclusive results. Several technical aspects have to be considered in VIVTAVI for a failing surgical bioprosthesis such as different radiopaque markers and different implantation techniques. Moreover, some complications, also potentially life threatening and dangerous, such as elevated postprocedural gradients and ostial coronary obstruction, have been reported anecdotally and sporadically, during this type of procedure ${ }^{[52,53]}$. This registry started in December 2010, with a total of 38 participating centers (Europe, North America, Australia etc.). The register contains data and procedural results from the mentioned centres that have experience of TAVI with the use of both balloon and self-expandable devices. Preliminary results were reported including 202 patients with degenerated bioprosthetic valves (aged 77.7 \pm 10.4 years; $52.5 \% \mathrm{men})^{[51]}$. Bioprosthesis mode of failure was stenosis $(n=85 ; 42 \%)$, regurgitation $(n=68$; $34 \%)$, or both $(n=49 ; 24 \%)$. Two devices have been implanted: Medtronic CoreValve ${ }^{\bullet}(n=124)$ and Edwards SAPIEN $^{\circ}(n=78)$. Procedural success was achieved in $93.1 \%$ of patients. Device malposition occurred in $15.3 \%$ of cases whereas ostial coronary obstruction was observed in $3.5 \%$ of patients. Post-procedural valve maximum and mean gradient were $28.4 \pm 14.1 \mathrm{mmHg}$ and $15.9 \pm 8.6 \mathrm{mmHg}$ respectively; about $95 \%$ of patients developed $\leq+1$ degree AR. All-cause 30-day mortality was $8.4 \%$, whereas, 1-year follow-up showed a survival rate of $85.8 \%$.

These preliminary data emerging from the Global Valve-in-Valve Registry allows us to consider the VIV strategy a possible alternative to conventional redo surgery in patients with degenerated bioprosthetic valves. Device malposition, ostial coronary obstruction, and post-procedural aortic stenosis remain important concerns against the routine application of this procedure. Thus, other studies and longer follow-up are needed to confirm its safety and efficacy in clinical practice.

\section{CONCLUSION}

TAVI may be considered as "first choice" and not as last chance in many patients with AS. TAVI has emerged as the standard of care in inoperable/high risk patients whereas several randomized trials have demonstrated similar results of TAVI compared with SAVR also in the intermediate/low risk subset. Moreover, the feasibility and safety of TAVI has been suggested also in patients with aortic bicuspid valve, pure $\mathrm{AR}$ and degenerative bioprosthetic surgical valves. Importantly, a careful risk assessment through surgical scores (STS, EuroSCORE etc.) is crucial, but other variables need to be considered such as frailty profile and specific anatomical elements (hostile chest, porcelain aorta). These factors are relevant for procedural success and long-term survival, but not included in the conventional scores possibly leading to underestimated risk classification. Surely improved procedural and technical experience, associated with an enhanced healthcare 
organization, will cause a widespread extension of TAVI indication; on the other hand, prosthesis durability remains an important issue and a longer follow-up is needed to confirm the effectiveness of TAVI in different settings.

\section{DECLARATIONS}

\section{Author's contributions}

All authors provided substantial contributions to conception, design, drafting the article or revising it critically for important intellectual content.

\section{Availability of data and materials}

Not applicable.

\section{Financial support and sponsorship}

None.

\section{Conflicts of interest}

All authors declare that there are no conflicts of interest.

\section{Ethical approval and consent to participate}

Not applicable.

\section{Consent for publication}

Not applicable.

\section{Copyright}

(c) The Author(s) 2018.

\section{REFERENCES}

1. Ross J Jr, Braunwald E. Aortic stenosis. Circulation 1968;38:61-7.

2. Cribier A, Eltchaninoff H, Bash A, Borenstein N, Tron C, Bauer F, Derumeaux G, Anselme F, Laborde F, Leon MB. Percutaneous transcatheter implantation of an aortic valve prosthesis for calcific aortic stenosis: first human case description. Circulation 2002;106:3006-8.

3. Baumgartner H, Falk V, Bax JJ, De Bonis M, Hamm C, Holm PJ, Iung B, Lancellotti P, Lansac E, Rodriguez Muñoz D, Rosenhek R, Sjögren J, Tornos Mas P, Vahanian A, Walther T, Wendler O, Windecker S, Zamorano JL; ESC Scientific Document Group. 2017 ESC/ EACTS Guidelines for the management of valvular heart disease. Eur Heart J 2017;38:2739-91.

4. Duncan A, Ludman P, Banya W, Cunningham D, Marlee D, Davies S, Mullen M, Kovac J, Spyt T, Moat N. Long-term outcomes after transcatheter aortic valve replacement in high-risk patients with severe aortic stenosis: the U.K. Transcatheter Aortic Valve Implantation Registry. JACC Cardiovasc Interv 2015;8:645-53.

5. Gilard M, Eltchaninoff H, Iung B, Donzeau-Gouge P, Chevreul K, Fajadet J, Leprince P, Leguerrier A, Lievre M, Prat A, Teiger E, Lefevre T, Himbert D, Tchetche D, Carrié D, Albat B, Cribier A, Rioufol G, Sudre A, Blanchard D, Collet F, Dos Santos P, Meneveau N, Tirouvanziam A, Caussin C, Guyon P, Boschat J, Le Breton H, Collart F, Houel R, Delpine S, Souteyrand G, Favereau X, Ohlmann P, Doisy V, Grollier G, Gommeaux A, Claudel JP, Bourlon F, Bertrand B, Van Belle E, Laskar M; FRANCE 2 Investigators. Registry of transcatheter aortic-valve implantation in high-risk patients. N Engl J Med 2012;366:1705-15.

6. Walther T, Hamm CW, Schuler G, Berkowitsch A, Kötting J, Mangner N, Mudra H, Beckmann A, Cremer J, Welz A, Lange R, Kuck KH, Mohr FW, Möllmann H; GARY Executive Board. Perioperative results and complications in 15,964 transcatheter aortic valve replacements: prospective data from the GARY registry. J Am Coll Cardiol 2015;65:2173-80.

7. Popma JJ, Adams DH, Reardon MJ, Yakubov SJ, Kleiman NS, Heimansohn D, Hermiller J Jr, Hughes GC, Harrison JK, Coselli J, Diez J, Kafi A, Schreiber T, Gleason TG, Conte J, Buchbinder M, Deeb GM, Carabello B, Serruys PW, Chenoweth S, Oh JK; CoreValve United States Clinical Investigators. Transcatheter aortic valve replacement using a self-expanding bioprosthesis in patients with severe aortic stenosis at extreme risk for surgery. J Am Coll Cardiol 2014;63:1972-81.

8. Smith CR, Leon MB, Mack MJ, Miller DC, Moses JW, Svensson LG, Tuzcu EM, Webb JG, Fontana GP, Makkar RR, Williams M, Dewey T, Kapadia S, Babaliaros V, Thourani VH, Corso P, Pichard AD, Bavaria JE, Herrmann HC, Akin JJ, Anderson WN, Wang D, Pocock SJ; PARTNER Trial Investigators. Transcatheter versus surgical aortic-valve replacement in high-risk patients. N Engl J Med 
2011;364:2187-98.

9. Adams DH, Popma JJ, Reardon MJ, Yakubov SJ, Coselli JS, Deeb GM, Gleason TG, Buchbinder M, Hermiller J Jr, Kleiman NS, Chetcuti S, Heiser J, Merhi W, Zorn G, Tadros P, Robinson N, Petrossian G, Hughes GC, Harrison JK, Conte J, Maini B, Mumtaz M, Chenoweth S, Oh JK; U.S. CoreValve Clinical Investigators. Transcatheter aortic-valve replacement with a self-expanding prosthesis. N Engl J Med 2014;370:1790-8.

10. Otto C, Kumbhani DJ, Alexander KP, Calhoon JH, Desai MY, Kaul S, Lee JC, Ruiz CE, Vassileva CM. 2017 ACC expert consensus decision pathway for transcatheter aortic valve replacement in the management of adults with aortic stenosis: a report of the American College of Cardiology Task Force on Clinical Expert Consensus Documents. J Am Coll Cardiol 2017;69:1313-46.

11. Kirtane AJ, Leon MB. The Placement of Aortic Transcatheter Valve (PARTNER) trial: clinical trials. Circulation 2012;125:3229-32.

12. Florath I, Albert A, Boening A, Ennker IC, Ennker J. Aortic valve replacement in octogenarians: identification of high-risk patients. Eur J Cardiothorac Surg 2010;37:1304-10.

13. Dewey TM, Brown D, Ryan WH, Her- bert MA, Prince SL, Mack MJ. Reliability of risk algorithms in predicting early and late operative outcomes in high-risk patients undergoing aortic valve replacement. J Thorac Cardiovasc Surg 2008;135:180-7.

14. Vahanian A, Alfieri OR, Al-Attar N, Antunes MJ, Bax J, Cormier B, Cribier A, De Jaegere P, Fournial G, Kappetein AP, Kovac J, Ludgate S, Maisano F, Moat N, Mohr FW, Nataf P, Pierard L, Pomar JL, Schofer J, Tornos P, Tuzcu M, van Hout B, von Segesser LK, Walther T. Transcatheter valve implantation for patients with aortic stenosis: a position statement from the European Association of Cardio-Thoracic Surgery (EACTS) and the European Society of Cardiology (ESC), in collaboration with the European Association of Percutaneous Cardiovascular Interventions (EAPCI). Eur J Cardiothorac Surg 2008;34:1-8.

15. Roques F, Nashef SA, Michel P; EuroSCORE study group. Risk factors for early mortality after valve surgery in Europe in the 1990s: lessons from the EuroSCORE pilot program. J Heart Valve Dis 2001;10:572-7; discussion 577-8.

16. Ferguson TB Jr, Dziuban SW Jr, Edwards FH, Eiken MC, Shroyer AL, Pairolero PC, Anderson RP, Grover FL. The STS National Database: current changes and challenges for the new millennium. Committee to Establish a National Database in Cardiothoracic Surgery, The Society of Thoracic Surgeons. Ann Thoracic Surg 2000;69:680-91.

17. Green P, Woglom AE, Genereux P, Daneault B, Paradis JM, Schnell S, Hawkey M, Maurer MS, Kirtane AJ, Kodali S, Moses JW, Leon MB, Smith CR, Williams M. The impact of frailty status on survival after transcatheter aortic valve replacement in older adults with severe aortic stenosis: a single-center experience. JACC Cardiovasc Interv 2012;5:974-81.

18. Anand A, Harley C, Visvanathan A, Shah ASV, Cowell J, MacLullich A, Shenkin S, Mills NL. The relationship between preoperative frailty and outcomes following transcatheter aortic valve implantation: a systematic review and meta-analysis. Eur Heart J Qual Care Clin Outcomes 2017;3:123-32.

19. Nishimura RA, Otto CM, Bonow RO, Carabello BA, Erwin JP 3rd, Guyton RA, O’Gara PT, Ruiz CE, Skubas NJ, Sorajja P, Sundt TM 3rd, Thomas JD; ACC/AHA Task Force Members. 2014 AHA/ACC Guideline for the management of patients with valvular heart disease: executive summary; a report of the American College of Cardiology/American Heart Association Task Force on Practice Guidelines. Circulation 2014;129:e650.

20. Leon MB, Smith CR, Mack M, Miller DC, Moses JW, Svensson LG, Tuzcu EM, Webb JG, Fontana GP, Makkar RR, Brown DL, Block PC, Guyton RA, Pichard AD, Bavaria JE, Herrmann HC, Douglas PS, Petersen JL, Akin JJ, Anderson WN, Wang D, Pocock S; PARTNER Trial Investigators. Transcatheter aortic-valve implantation for aortic stenosis in patients who cannot undergo surgery. N Engl J Med 2010;363:1597-607.

21. Shroyer AL, Coombs LP, Peterson ED, Eiken MC, DeLong ER, Chen A, Ferguson TB Jr, Grover FL, Edwards FH; Society of Thoracic Surgeons. The Society of Thoracic Surgeons: 30-day operative mortality and morbidity risk models. Ann Thorac Surg 2003;75:1856-64.

22. Mack MJ, Leon MB, Smith CR, Miller DC, Moses JW, Tuzcu EM, Webb JG, Douglas PS, Anderson WN, Blackstone EH, Kodali SK, Makkar RR, Fontana GP, Kapadia S, Bavaria J, Hahn RT, Thourani VH, Babaliaros V, Pichard A, Herrmann HC, Brown DL, Williams M, Akin J, Davidson MJ, Svensson LG; PARTNER 1 trial investigators. 5-year outcomes of transcatheter aortic valve replacement or surgical aortic valve replacement for high surgical risk patients with aortic stenosis (PARTNER 1): a randomised controlled trial. Lancet 2015;385:2477-84.

23. Kapadia SR, Leon MB, Makkar RR, Tuzcu EM, Svensson LG, Kodali S, Webb JG, Mack MJ, Douglas PS, Thourani VH, Babaliaros VC, Herrmann HC, Szeto WY, Pichard AD, Williams MR, Fontana GP, Miller DC, Anderson WN, Akin JJ, Davidson MJ, Smith CR; PARTNER trial investigators. 5-year outcomes of transcatheter aortic valve replacement compared with standard treatment for patients with inoperable aortic stenosis (PARTNER 1): a randomised controlled trial. Lancet 2015;385:2485-91.

24. Thomas M, Schymik G, Walther T, Himbert D, Lefèvre T, Treede H, Eggebrecht H, Rubino P, Michev I, Lange R, Anderson WN, Wendler O. Thirty-day results of the SAPIEN aortic Bioprosthesis European Outcome (SOURCE) Registry: A European registry of transcatheter aortic valve implantation using the Edwards SAPIEN valve. Circulation 2010;122:62-9.

25. Moat NE, Ludman P, de Belder MA, Bridgewater B, Cunningham AD, Young CP, Thomas M, Kovac J, Spyt T, MacCarthy PA, Wendler O, Hildick-Smith D, Davies SW, Trivedi U, Blackman DJ, Levy RD, Brecker SJ, Baumbach A, Daniel T, Gray H, Mullen MJ. Longterm outcomes after transcatheter aortic valve implantation in high-risk patients with severe aortic stenosis: the U.K. aortic valve implantation (United Kingdom Transcatheter Aortic Valve Implantation) Registry. J Am Coll Cardiol 2011;58:2130-8.

26. Brown DL. Expanding indications for TAVR: The preferred procedure in intermediate-risk patients? Cleve Clinic J Med 2017;84:e10-4.

27. Stähli BE, Tasnady H, Lüscher TF, Gebhard C, Mikulicic F, Erhart L, Bühler I, Landmesser U, Altwegg L, Wischnewsky MB, Grünenfelder J, Falk V, Corti R, Maier W. Early and late mortality in patients undergoing transcatheter aortic valve implantation: comparison of the Novel EuroSCORE II with Established Risk Scores. Cardiology 2013;126:15-23.

28. Leon MB, Smith CR, Mack MJ, Makkar RR, Svensson LG, Kodali SK, Thourani VH, Tuzcu EM, Craig Miller D, Herrmann HC, 
Doshi D, Cohen DJ, Pichard AD, Kapadia S, Dewey T, Babaliaros V, Szeto WY, Williams MR, Kereiakes D, Zajarias A, Greason KL, Whisenant BK, Hodson RW, Moses JW, Trento A, Brown DL, Fearon WF, Pibarot P, Hahn RT, Jaber WA, Anderson WN, Alu MC, Webb JG; PARTNER 2 Investigators. Transcatheter or surgical aortic-valve replacement in intermediate-risk patients. N Engl J Med 2016;374:1609-20.

29. Reardon MJ, Van Mieghem NM, Popma JJ, Kleiman NS, Søndergaard L, Mumtaz M, Adams DH, Deeb GM, Maini B, Gada H, Chetcuti S, Gleason T, Heiser J, Lange R, Merhi W, Oh JK, Olsen PS, Piazza N, Williams M, Windecker S, Yakubov SJ, Grube E, Makkar R, Lee JS, Conte J, Vang E, Nguyen H, Chang Y, Mugglin AS, Serruys PW, Kappetein AP; SURTAVI Investigators. Surgical or transcatheter aortic-valve replacement in intermediate-risk patients. N Engl J Med 2017;376:1321-31.

30. Thyregod HG, Steinbrüchel DA, Ihlemann N, Nissen H, Kjeldsen BJ, Petursson P, Chang Y, Franzen OW, Engstrøm T, Clemmensen P, Hansen PB, Andersen LW, Olsen PS, Søndergaard L. Transcatheter versus surgical aortic valve replacement in patients with severe aortic valve stenosis: 1-year results from the All-Comers NOTION Randomized Clinical Trial. J Am Coll Cardiol 2015;65:2184-94.

31. Thyregod HG. Five-year outcomes from the All-Comers Nordic Aortic Valve Intervention Randomized Clinical Trial in patients with severe aortic valve stenosis. ACC Annual Congress; 2018.

32. Wenaweser P, Stortecky S, Schwander S, Heg D, Huber C, Pilgrim T, Gloekler S, O’Sullivan CJ, Meier B, Juni P, Carrel T, Windecker $\mathrm{S}$. Clinical outcomes of patients with estimated low or intermediate surgical risk undergoing transcatheter aortic valve implantation. Eur Heart J 2013;34:1894-905.

33. Tamburino C,Barbanti M, D'Errigo P, Ranucci M, Onorati P, Covello RD, Santini F, Rosato S, Santoro G, Fusco D, Grossi C, Seccareccia F; OBSERVANT Research Group. 1-year outcomes after transfemoral transcatheter or surgical aortic valve replacement: results from the Italian OBSERVANT Study. J Am Coll Cardiol 2015;66:804-12.

34. Tarantini G, Nai Fovino L, Gers BJ. Transcatheter aortic valve implantation in lower-risk patients: what is the perspective? Eur Heart J 2018;39:1-12.

35. Thourani VH, Forcillo J, Szeto WY, Kodali SK, Blackstone EH, Lowry AM, Semple M, Rajeswaran J, Makkar RR, Williams MR, Bavaria JE, Herrmann HC, Maniar HS, Babaliaros VC, Smith CR, Trento A, Corso PJ, Pichard AD, Craig Miller D, Svensson LG, Kapadia S, Ailawadi G, Suri RM, Greason KL, Hahn RT, Jaber WA, Alu MC, Leon MB, Mack MJ; PARTNER Trial Investigators. Outcomes in 937 intermediate-risk patients undergoing surgical aortic valve replacement in PARTNER-2A. Ann Thorac Surg 2018;105:1322-9.

36. Garcia S, Kelly R, Mbai M, Gurevich S, Oestreich B, Yannopoulos D, Adabag S. Outcomes of intermediate-risk patients treated with transcatheter and surgical aortic valve replacement in the Veterans Affairs Healthcare System: a single center 20-year experience. Catheter Cardiovasc Interv 2018; doi: 10.1002/ccd.27478.

37. Tarantini G, Gasparetto V, Napodano M, Fraccaro C, Gerosa G, Isabella G. Valvular leak after transcatheter aortic valve implantation: a clinician update on epidemiology, pathophysiology and clinical implications. Am J Cardiovasc Dis 2011;1:312-20.

38. Bauer T, Linke A, Sievert H, Kahlert P, Hambrecht R, Nickenig G, Hauptmann KE, Sack S, Gerckens U, Schneider S, Zeymer U, Zahn R. Comparison of the effectiveness of transcatheter aortic valve implantation in patients with stenotic bicuspid versus tricuspid aortic valves (from the German TAVI Registry). Am J Cardiol 2014;113:518-21.

39. Phan K, Wong S, Phan S, Ha H, Qian P, Yan TD. Transcatheter aortic valve implantation (aortic valve implantation) in patients with bicuspid aortic valve stenosis--systematic review and meta-analysis. Heart Lung Circ 2015;24:649-59.

40. Sannino A, Cedars A, Stoler RC, Szerlip M, Mack MJ, Grayburn PA. Comparison of efficacy and safety of transcatheter aortic valve implantation in patients with bicuspid versus tricuspid aortic valves. Am J Cardiol 2017;120:1601-6.

41. Praz F, Windecker S, Huber C, Carrel T, Wenaweser P. Expanding indications of transcatheter heart valve interventions. J Am Coll Cardiol Intv 2015;8:1777-96.

42. Yoon SH, Schmidt T, Bleiziffer S, Schofer N, Fiorina C, Munoz-Garcia AJ, Yzeiraj E, Amat-Santos IJ, Tchetche D, Jung C, Fujita B, Mangieri A, Deutsch MA, Ubben T, Deuschl F, Kuwata S, De Biase C, Williams T, Dhoble A, Kim WK, Ferrari E, Barbanti M, Vollema EM, Miceli A, Giannini C, Attizzani GF, Kong WKF, Gutierrez-Ibanes E, Jimenez Diaz VA, Wijeysundera HC, Kaneko H, Chakravarty T, Makar M, Sievert H, Hengstenberg C, Prendergast BD, Vincent F, Abdel-Wahab M, Nombela-Franco L, Silaschi M, Tarantini G, Butter C, Ensminger SM, Hildick-Smith D, Petronio AS, Yin WH, De Marco F, Testa L, Van Mieghem NM, Whisenant BK, Kuck KH, Colombo A, Kar S, Moris C, Delgado V, Maisano F, Nietlispach F, Mack MJ, Schofer J, Schaefer U, Bax JJ, Frerker C, Latib A, Makkar RR. Transcatheter aortic valve replacement in pure native aortic valve regurgitation. J Am Coll Cardiol 2017;70:2752-63.

43. Franzone A, Piccolo R, Siontis GC, Lanz J, Stortecky S, Praz F, Roost E, Vollenbroich R, Windecker S, Pilgrim T. Transcatheter aortic valve replacement for the treatment of pure native aortic valve regurgitation: a systematic review. JACC Cardiovasc Interv 2016;9:230817.

44. Sawaya FJ, Deutsch MA, Seiffert M, Yoon SH, Codner P, Wickramarachchi U, Latib A, Petronio AS, Rodés-Cabau J, Taramasso M, Spaziano M, Bosmans J, Biasco L, Mylotte D, Savontaus M, Gheeraert P, Chan J, Jørgensen TH, Sievert H, Mocetti M, Lefèvre T, Maisano F, Mangieri A, Hildick-Smith D, Kornowski R, Makkar R, Bleiziffer S, Søndergaard L, De Backer O. Safety and efficacy of transcatheter aortic valve replacement in the treatment of pure aortic regurgitation in native valves and failing surgical bioprostheses: results from an International Registry Study. JACC Cardiovasc Interv 2017;10:1048-56.

45. Brown JM, O’Brien SM, Wu C, Sikora JA, Griffith BP, Gammie JS. Isolated aortic valve replacement in North America comprising 108,687 patients in 10 years: changes in risks, valve types, and outcomes in the Society of Thoracic Surgeons National Database. J Thorac Cardiovasc Surg 2009; 137:82-90.

46. Ussia GP, Barbanti M, Petronio AS, Tarantini G, Ettori F, Colombo A, Violini R, Ramondo A, Santoro G, Klugmann S, Bedogni F, Maisano F, Marzocchi A, Poli A, De Carlo M, Napodano M, Fiorina C, De Marco F, Antoniucci D, de Cillis E, Capodanno D, Tamburino C. Transcatheter aortic valve implantation: 3-year outcomes of selfexpanding CoreValve prosthesis. Eur Heart J 2012;33:969-76. 
47. Rode s-Cabau J, Dumont E, Doyle D, Lemieux J. Transcatheter valve- in-valve implantation for the treatment of stentless aortic valve dysfunction. J Thorac Cardiovasc Surg 2010;140:246-8.

48. Eggebrecht H, Scha fer U, Treede H, Boekstegers P, Babin-Ebell J, Ferrari M, Mo '1lmann H, Baumgartner H, Carrel T, Kahlert P, Lange P, Walther T, Erbel R, Mehta RH, Thielmann M. Valve-in-valve transcatheter aortic valve implantation for degenerated bioprosthetic heart valves. JACC Cardiovasc Interv 2011;4:1218-27.

49. David TE, Ivanov J, Armstrong S, Feindel CM, Cohen G. Late results of heart valve replacement with the Hancock II bioprosthesis. J Thorac Cardiovasc Surg 2001;121:268-77.

50. Maganti M, Rao V, Armstrong S, Feindel CM, Scully HE, David TE. Redo valvular surgery in elderly patients. Ann Thorac Surg 2009;87:521-5.

51. Dvir D, Webb J, Brecker S, Bleiziffer S, Hildick-Smith D, Colombo A, Descoutures F, Hengstenberg C, Moat NE, Bekeredjian R, Napodano M, Testa L, Lefevre T, Guetta V, Nissen H, Hernández JM, Roy D, Teles RC, Segev A, Dumonteil N, Fiorina C, Gotzmann M, Tchetche D, Abdel-Wahab M, De Marco F, Baumbach A, Laborde JC, Kornowski R. Transcatheter aortic valve replacement for degenerative bioprosthetic surgical valves: results from the global valve-in-valve registry. Circulation 2012;126:2335-44.

52. Seiffert M, Conradi L, Baldus S, Knap M, Schirmer J, Franzen O, Koschyk D, Meinertz T, Reichenspurner H, Treede H. Impact of patient- prosthesis mismatch after transcatheter aortic valve-in-valve implantation in degenerated bioprostheses. J Thorac Cardiovasc Surg 2011;143: 617-24.

53. Gurvitch R, Cheung A, Bedogni F, Webb JG. Coronary obstruction following transcatheter aortic valve-in-valve implantation for failed surgical bioprostheses. Catheter Cardiovasc Interv 2011;77:439-44. 